\title{
Safety Regulation vs. Liability with Heterogeneous Probabilities of Suit
}

\author{
Sébastien Rouillon * \\ March 26, 2007 \\ Université de Bordeaux 4 \\ GRETHA
}

\begin{abstract}
Summary: This article deals with the regulation of activities that entails risk by means of regulatory standard and liability. The original assumption is that the probability that parties might escape liability is variable among the population. The use of each instrument separately is first considered. Under liability, the optimal damages are calculated. From this, it is shown that regulation is superior to liability if the harm is not too variable within the population and if the probability of suit is sufficiently variable within the population, and conversely. The use of both instruments at the same time is then analyzed. The optimal combination of a safety standard and a liability schedule is derived. From this, it is proved that a joint use of regulation and liability is always optimal and that the instruments should be designed in a less stringent manner when used jointly.
\end{abstract}

Keywords: liability, regulation.

JEL: D82, K13, K32.

\section{Introduction}

In a pioneering article, Shavell (1984a) compares the ability of safety regulation and of liability rules, to economize the social costs of hazardous activities (including the costs of care and accident). The main premises of the model are the following. On the one hand, the impacts of an accident are assumed known to the injurer ex ante, but observable to a third party only ex post. The judge possesses thus an informational advantage, compared to the regulator, for a regulatory standard must be defined ex ante, whereas liability intervenes ex post. On the other hand, in reality, liability rules will work imperfectly when the harm that some parties might cause may exceed their assets or when they might escape suit. From these premises, Shavell obtains the following consequences. The use of regulation is superior if the variability of the harm is sufficiently small and if the factors of dilution of the liability are sufficiently important, and conversely (proposition 3). A joint use of regulation and liability can be socially beneficial when the factors under liability that reduce the incentives to take care are not too important (proposition 4).

Schmitz (2000) pursues the question, abandoning an implicit assumption in Shavell (1984a), namely that the judge is not allowed to use punitive damages (i.e. damages in excess of the harm done). This amendment yields some modifications in the conclusions. When wealth does not vary among injurers, regulation is superior if, and only if, wealth is less than a certain threshold. More importantly, if the judge is allowed to use punitive damages, it is never optimal to use both instruments at the same time (proposition 1). When wealth varies among individuals, the optimality of a joint use of regulation and liability is restored,

\footnotetext{
* Corresponding address: Sébastien Rouillon, Avenue L. Duguit, 33608 Pessac cedex, France, tel: +033 (0)5 56 8425 85, email: rouillon@u-bordeaux4.fr
} 
provided that the proportion of poor injurers in the population is sufficiently large (proposition 2).

The present article continues this line of research, under different assumptions. In accordance with Schmitz (2000), it is assumed throughout that the judge sets damages at a level so as to induce optimal care on the part of the injurers. In other words, punitive damages are permitted. Therefore, a failure of the liability rules is to be found in enforcement errors only. We depart from Shavell (1984a) and Schmitz (2000) in two respects. As a simplifying assumption, we choose to exclude the judgment-proof problem (i.e. the fact that liable parties might escape liability for damage done thanks to insolvency). This restriction is made so as to focus on the effects of the possibility that the injurers might escape liability. The originality of the analysis derives then from the assumption that the probability that some parties might escape suit varies in the population and is not observable by a third party. Although emphasized by Schmitz (2000), to our knowledge, this possibility has never been considered in the literature.

Under these premises, it is shown below that even if liable parties can be asked to pay for punitive damages, liability will fail to induce optimal behavior of the injurers. This conclusion contradicts Schmitz (2000) and results from the judge's incomplete information. Indeed, as Schmitz proves, total damages equal to $(1 / q) h$ are required to induce an injurer, who can cause a harm $h$ and who expects to be found liable with a probability $q$, to apply the socially optimal amount of precaution. However, if the probability $q$ is unobservable to a third party, this rule will not be of help, for the judge will be bound to ask liable parties for a uniform payment, independent of their probability of being found liable. The injurers, albeit liable for the same damages $f$ ex post, will actually differ in the care they take, depending on their personal expected damages $q f$. Therefore, under incomplete information, another rule must be found. We derive it below and discuss its properties (proposition 1).

In Schmitz (2000), the only reason why regulation could be superior to liability is if liable parties are poor enough. For the reasons given above, this is no longer true when the probability that a party might escape liability varies among injurers. Assuming that injurers are always able to pay for the damages, we show that regulation is better if the variability of harm is sufficiently small and if the variability of the probability of suit is sufficiently large, and conversely (proposition 2).

Our results also depart from Schmitz concerning the advantages to be gained from a joint use of regulation and liability. We first calculate the optimal values of a regulatory standard and of damages when these instruments are used together (propositions 3 and 4). We then find that a combination of regulation and liability is always optimal when the probability of being found liable varies among the population. Safety regulation guarantees that the potential injurers who may cause a small harm and/or who may have a small chance of being found liable will take the minimum precaution required, while liability rules strengthen the level of care in the rest of the population and ensure a better fit with the harm done.

The discussion is organized as follows. Section 2 sets out the basic model and deals with the situation where regulation and liability are used separately. Section 3 is devoted to the joint use of these instruments.

\section{The basic model}

We build on the model of Schmitz (2000). Parties are risk-neutral and can cause accident due to their economic activities. The potential injurers can take precaution to reduce the probability of causing an accident. We denote $x$, with $0 \leq x \leq 1$, the verifiable level of care chosen by an injurer, normalized so that an accident will be caused by an injurer with 
probability $1-x$. The cost of taking precautions is given by the function $c(x)$. It is assumed to be strictly increasing, twice differentiable and strictly convex, with $c(0)=c^{\prime}(0)=0$ and $c^{\prime}(x)$ $\rightarrow \infty$ when $x \rightarrow 1$. Let $h$ be the magnitude of harm if an accident occurs. Only injurers know the harm they may cause when they decide how much care to take. However, it is common knowledge that $h$ is distributed according to a density function $\phi(h)$, with $\phi(h)>0$ for all $h \in$ $[a, b]$. Once an accident has occurred, $h$ can be verified.

Social optimum. The socially optimal level of care that an injurer of type $h$ should choose minimizes the expected costs of care and of harm done:

$$
c(x)+(1-x) h .
$$

Given the properties of the cost function, the socially optimal level of care satisfies the firstorder condition:

$$
c^{\prime}(x)-h=0 .
$$

In other words, an amount of precaution minimizes the social cost if, and only if, the marginal cost of precaution equals the harm.

For all $h$, let $x^{*}(h)$ be the solution of (1). By implicit differentiation, it follows that $x^{*}(h)$ is strictly increasing in $h$ :

$$
\left(x^{*}\right)^{\prime}(h)=1 / c^{\prime \prime}\left(x^{*}(h)\right)>0 .
$$

Regulation only. The first instrument to be considered is ex ante safety regulation. This instrument is completely characterized by a single regulatory standard $s$, with $0 \leq s \leq 1$, to which parties must adhere in order to engage in activity. Since taking precaution is costly, no injurer will voluntarily choose a higher level of care, so that under regulation, each injurer complies with the standard, choosing $x=s$, independent of his type.

Therefore, the socially optimal standard can be found by minimizing over $s$ the expected social cost:

$$
c(s)+(1-s) E(h),
$$

where $E(h)$ stands for the mean of $h$ in the population. A solution to this problem satisfies the first-order condition:

$$
c^{\prime}(s)-E(h)=0 .
$$

In other words, the socially optimal standard is such that the marginal cost of precaution equals the expected harm. By definition of $x^{*}(h)$, the solution is $s^{*}=x^{*}(E(h))$.

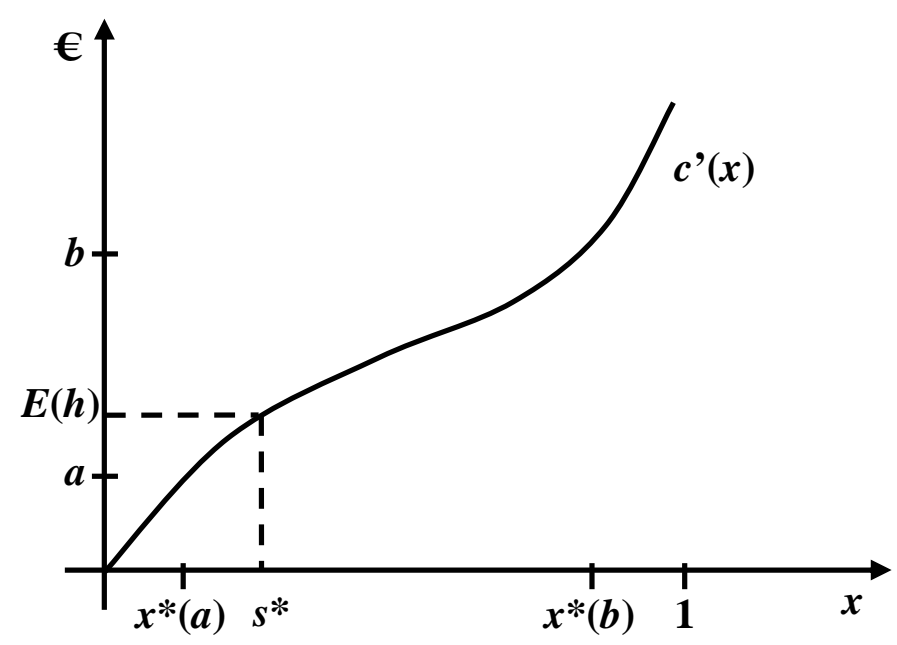

Figure 1 - Optimal regulatory standard 
Liability only. Ex post liability is now considered. It is assumed throughout that liability is strict, so that an injurer who has caused an accident is required to pay damages $f$ to the victim, regardless of how much care has been taken $\left({ }^{1}\right)$.

Let us first summarize the standard theory of liability (Polinsky and Shavell, 1998a, 1998b; Kaplow and Shavell, 2002). When injurers are found liable with certainty, a well-known result is that damages should equal the harm, i.e. $f=h$, to induce them to choose the socially optimal amount of care. However, in reality, liable parties sometimes escape liability, because they may be hard to identify or because victims may choose not to bring suit. To deal with that problem, Shavell (1984a) defines $q$ as the probability that a party is actually found liable and asked to pay for damages when he ought to be, with $0<q<1$. Polinsky and Shavell (1998a, 1998b) review the implications of such assumptions. The general principle is that damages should be raised so that injurers always face expected damages equal to the harm they cause, i.e. $q f=h$. Therefore, the total damages should equal the harm multiplied by the reciprocal of the probability that the injurer will be found liable when he ought to be, i.e. $f=$ $h / q\left({ }^{2}\right)$. It also follows from this principle that total damages will exceed harm. The difference between total damages and compensatory damages, i.e. $f-h=(1 / q-1) h$, is called punitive damages.

We depart from the basic theory by considering the case where probability $q$ varies among injurers and that there exists asymmetric information about it. Precisely, it is assumed throughout that:

- an injurer knows his own $q$;

- a third party will never observe it;

- it is common knowledge that $q$ takes the values $q_{0}$ and $q_{1}$, with $q_{0}<q_{1} \leq 1$, and that the proportion of types $q_{0}$ in the population is $r$, with $0<r<1$.

This assumption of variable probabilities of suit is easily justified. The circumstances of an accident and, therefore, the evidence that the injured party and the judge are able to collect can vary from one injurer to another. Formally, there might exist two types of accident, one for which Nature sends a signal about the identity of the injurer who caused the accident with a probability $q_{0}$, and another for which Nature sends the same signal with a probability $q_{1}$.

The following analysis aims at determining the value of the total damages so that incentives be optimal, under these informational assumptions. The results will be compared to the basic theory just summarized.

Facing damages $f$, an injurer of type $q$ chooses the amount of precaution $x$ to minimize his expected private cost:

$$
c(x)+(1-x) q f .
$$

The optimal solution is $x=x^{*}(q f)$ and satisfies the first-order condition:

$$
c^{\prime}(x)-q f=0 .
$$

It is such that the marginal cost of precaution equals the expected damages and thus depends on $q$.

\footnotetext{
$\left({ }^{1}\right)$ Under a negligence rule (under which a party is declared liable if his precautionary level is judged inadequate by the court), the court could remedy its imperfect information about $q$, for it is always possible to enforce $x^{*}(h)$ through the use of sufficiently large damages (Rouillon, 2007). Therefore, the present analysis is best suited to the case where the court cannot verify the level of care of the injurers with sufficient accuracy. For example, the level of care could be observable ex ante, but not ex post, if the occurrence of an accident destroys evidence of precaution.

$\left({ }^{2}\right)$ The multiplier $(1 / q)$ is referred as the total damage multiplier (Polinsky and Shavell, 1998a, 1998b) or as the punitive multiple (Cooter, 1991).
} 
From this, it follows that, if a liability $f$ is set for a type $h$, the expected social cost equals:

where:

$$
r\left[c\left(x_{0}\right)+\left(1-x_{0}\right) h\right]+(1-r)\left[c\left(x_{1}\right)+\left(1-x_{1}\right) h\right],
$$

$$
\begin{aligned}
& x_{0}=x^{*}\left(q_{0} f\right), \\
& x_{1}=x^{*}\left(q_{1} f\right),
\end{aligned}
$$

and the social problem is to choose $f$ to minimize it.

Figure 2 below illustrates the problem. For harm $h$, the socially optimal care is $x^{*}(h)$ (see point $A$ in figure 2). This outcome cannot in fact be achieved, due to the heterogeneity of $q$. Indeed, let us assume that the injurers are asked to pay $f$ when they are found liable for harm (in figure 2, $f$ is set such that $q_{0} f<h<q_{1} f$ ). In the face of these damages, an injurer of type $q_{0}$ has an incentive to choose $x_{0}=x^{*}\left(q_{0} f\right)$ and an injurer of type $q_{1}$ has an incentive to choose $x_{1}$ $=x^{*}\left(q_{1} f\right)$. These behaviors yield social costs in excess of the first-best. The social problem is to determine $f$ in order to minimize these costs.

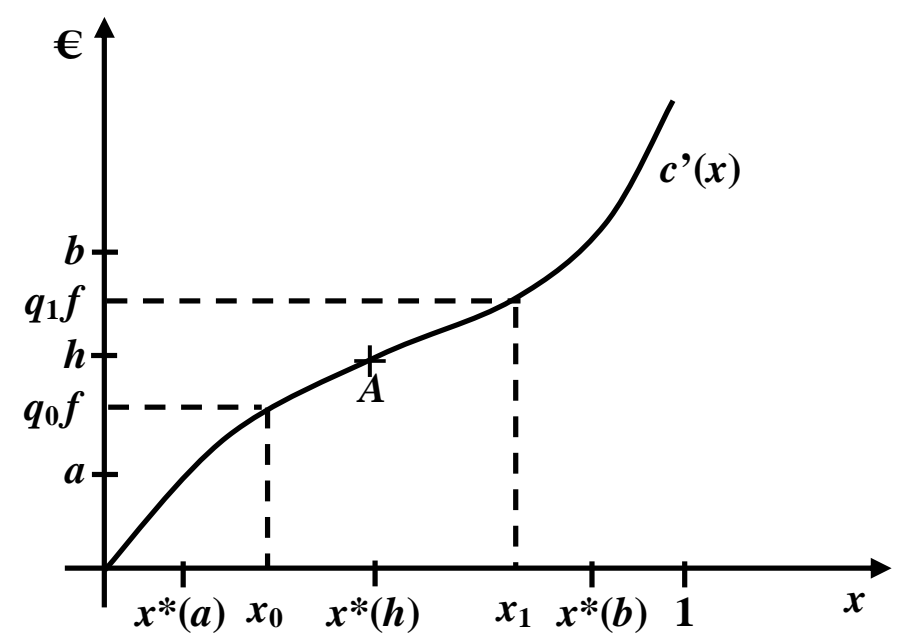

Figure 2 - Optimal Damages

Proposition 1 below solves this problem. It is assumed here and elsewhere that $c "(x)$ is differentiable. The proof is given in the appendix. It clarifies the conditions required for $q_{1} / q_{0}$.

Proposition 1: If $q_{1} / q_{0}$ is sufficiently small, the social problem admits a unique solution $f=$ $f^{*}(h)$, for all $h$, which satisfies the first-order condition:

$$
\left[r\left(q_{0}\right)^{2} / C_{0}+(1-r)\left(q_{1}\right)^{2} / C_{1}\right] f^{*}(h)=\left[r q_{0} / C_{0}+(1-r) q_{1} / C_{1}\right] h,
$$

where $C_{0}=c^{\prime \prime}\left(x^{*}\left(q_{0} f^{*}(h)\right)\right)>0$ and $C_{1}=c^{\prime \prime}\left(x^{*}\left(q_{1} f^{*}(h)\right)\right)>0$. It lies strictly between $h / q_{1}$ and $h / q_{0}$. It is increasing and differentiable in $h$.

Using figure 2, it is easily seen why the optimal total damages should be chosen between $h / q_{1}$ and $h / q_{0}$ (these bounds define the damages that would incite injurers of type $q_{0}$ and $q_{1}$, respectively, to adopt the socially optimal care $x^{*}(h)$ ). Indeed, if damages $f$ were such that $q_{0} f$ $\geq h$ or $q_{1} f \leq h$ in figure 2 , it would be possible to modify them so as to induce both types of injurers, simultaneously, to choose a point closest to point $A$.

Regulation vs. liability. The difference in expected social costs between the situation where liability alone is employed and that where the optimal regulatory standard is used alone equals: 


$$
\int_{a}^{b}\left\{\begin{array}{c}
r\left[c\left(x^{*}\left(q_{0} f^{*}(h)\right)\right)+\left(1-x^{*}\left(q_{0} f^{*}(h)\right)\right) h\right] \\
\left.+(1-r)\left[c\left(x^{*}\left(q_{1} f^{*}(h)\right)\right)+\left(1-x^{*}\left(q_{1} f^{*}(h)\right)\right) h\right)\right] \\
-\left[c\left(s^{*}\right)+\left(1-s^{*}\right) h\right]
\end{array}\right\} \phi(h) \mathrm{d} h
$$

From this, we obtain the following proposition.

Proposition 2: Regulation is superior to liability when the variability of $h$ is small enough among parties and when the variability of $q$ is large enough among parties (i.e. when $r$ is sufficiently close to a given $\underline{r}$ ); otherwise, liability is superior to regulation.

The proof is given in the appendix. The main arguments can be summarized as follows, using figure 3. The expected social cost under liability, denoted $L(r)$, is shown to have a minimum for $r=0$ or $r=1$, equal to the first-best expected social cost, and to be a strictly concave function. It follows that $L$ admits a unique maximum at $r=\underline{r}$ and is reversed Ushaped (cf. figure 3). In proposition 2, the variability of $q$ is said to be larger when $r$ is chosen closer to $\underline{r}$ (for example, in figure 3, the variability of $q$ is said to be larger when $r=r_{1}$ than when $\left.r=r_{0}\right)$. Under regulation, the expected social cost, denoted $R(\phi)$, can be made arbitrarily close to the first-best expected social cost, by letting the distribution of $h$ be sufficiently concentrated around the mean $E(h)$, and is an increasing function of the dispersion of $h$. Altogether, these elements imply that there exist distributions of $h$ and $q$ such that $R(\phi)=L(r)$ and, taking this equation as a point of departure, regulation becomes preferable if the distribution of $h$ is more concentrated and if the distribution of $q$ is more dispersed, in the sense given above, and conversely.

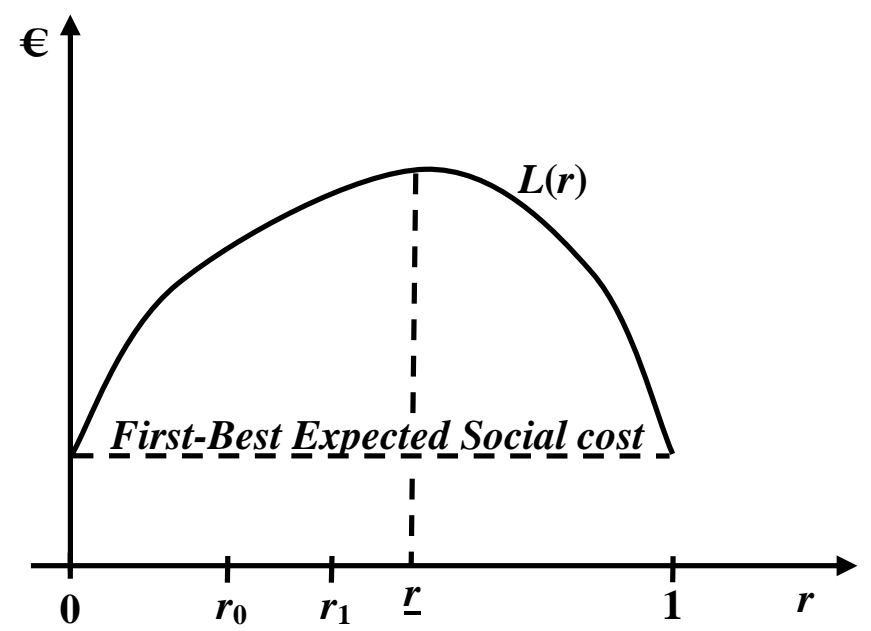

Figure 3 - Expected social cost under liability as a function of $r$.

\section{Joint use of safety regulation and liability}

In this section, we examine whether ex ante safety regulation and ex post liability should be used together.

To minimize his expected cost, an injurer of types $h$ and $q$, facing a regulatory standard $s$ and a liability $f$, has an incentive to comply with $s$, if $x^{*}(q f) \leq s$, and if not, to choose an amount of precaution $x^{*}(q f)$. In all cases, his amount of precaution is given by $\max \left\{s, x^{*}(q f)\right\}$.

From this, the social problem is to choose $s$ and $f(h)$, for all $h$, to minimize (omitting the argument $h$ of $x_{0}(h)$ and $x_{1}(h)$, to simplify our notations): 


$$
\int_{a}^{b}\left\{r\left[c\left(x_{0}\right)+\left(1-x_{0}\right) h\right]+(1-r)\left[c\left(x_{1}\right)+\left(1-x_{1}\right) h\right]\right\} \phi(h) d h
$$

subject to:

for all $h$.

$$
\begin{aligned}
& x_{0}=\max \left\{s, x^{*}\left(q_{0} f(h)\right)\right\}, \\
& x_{1}=\max \left\{s, x^{*}\left(q_{1} f(h)\right)\right\},
\end{aligned}
$$

Optimal liability schedule. The safety standard $s$ being given, this section is devoted to the determination of the optimal liability.

Define $\underline{h}$ as the harm for which $s$ would be socially optimal (i.e. $c^{\prime}(s)=\underline{h}$ or, equivalently, $s$ $=x^{*}(\underline{h})$ ). Given that $x^{*}(h)$ is increasing, the incentive constraints (7a) and (7b) allow three possible outcomes:

(R) Regulation: if $f$ is small enough (i.e. if $q_{1} f \leq \underline{h}$ ), the injurers adopt $s$;

(J) Joint: if $f$ has an intermediate value (i.e. if $q_{0} f \leq \underline{h}<q_{1} f$ ), an injurer of type $q_{0}$ follows $s$ and an injurer of type $q_{1}$ chooses $x^{*}\left(q_{1} f\right)$;

(L) Liability: if $f$ is large (i.e. if $\underline{h}<q_{0} f$ ), both types $q$ of injurers choose $x^{*}(q f)$.

Let $f(h)$, for all $h$, be the optimal liability schedule to be derived. Below, we built it in three steps.

Step 1: Introduce only outcome (R). Hence, provisionally, for all $h$ : the liability schedule is set such that $f(h) \leq \underline{h} / q_{1}$; the injurers of both type follow $s=x^{*}(\underline{h})$.

Step 2: Let us now build on our previous step, by making use of outcome (J). When $h \leq \underline{h}$, the safety standard $s$ is stringent enough. A liability inducing an even larger amount of care would thus only worsen the situation. Hence, for all $h \leq \underline{h}, f(h)$ must be left unchanged, with respect to Step 1 . When $h>\underline{h}$, the safety standard becomes too small. As far as only outcome (J) is concerned, it is clear that damages $f=\min \left\{h / q_{1}, \underline{h} / q_{0}\right\}$ are socially optimal, in order to induce an injurer of type $q_{1}$ to care an amount $x^{*}\left(q_{1} f\right)$ as close as possible to $x^{*}(h)$. Thus, whenever $h$ $>\underline{h}$, the liability schedule must be revised below, so that $f(h)=\min \left\{h / q_{1}, \underline{h} / q_{0}\right\}$, and, as a result, an injurer of type $q_{0}$ will follow $s=x^{*}(\underline{h})$ and an injurer of type $q_{1}$ will choose $x^{*}\left(\min \left\{h,\left(q_{1} / q_{0}\right) \underline{h}\right\}\right)$.

Step 3: Let us finally consider outcome (L). When $h \leq \underline{h}$, as argued in step $2, f(h)$ should be unchanged. When $h>\underline{h}$, we proceed as follows. We know from Proposition 1 that, when liability only is used, $f=f^{*}(h)$ is socially optimal, whatever the value of $h$. Thus, we compare the situation inherited from step 2, where injurers of types $q_{0}$ and $q_{1}$ choose $s$ and $x^{*}(\min \{h$, $\left.\left.\left(q_{1} / q_{0}\right) \underline{h}\right\}\right)$, respectively, with that where they choose $x^{*}\left(q_{0} f^{*}(h)\right)$ and $x^{*}\left(q_{1} f^{*}(h)\right)$, respectively. We define $D(\underline{h}, h)$ as the difference in expected social cost between these two outcomes:

$$
\begin{aligned}
D(\underline{h}, h)= & \left.\left\{r[c(s)-s h]+(1-r)\left[c\left(x^{*}\left(\min \left\{h,\left(q_{1} / q_{0}\right) \underline{h}\right\}\right)\right)-x^{*}\left(\min \left\{h,\left(q_{1} / q_{0}\right) \underline{h}\right\}\right)\right) h\right]\right\} \\
& -\left\{r\left[c\left(x^{*}\left(q_{0} f^{*}(h)\right)\right)-x^{*}\left(q_{0} f^{*}(h)\right) h\right]+(1-r)\left[c\left(x^{*}\left(q_{1} f^{*}(h)\right)\right)-x^{*}\left(q_{1} f^{*}(h)\right) h\right]\right\} .
\end{aligned}
$$

Then, at each $h$ where $D(\underline{h}, h)>0$, we update the liability schedule, by letting $f(h)=f^{*}(h)$. Finally, we check that, whenever $D(\underline{h}, h)>0$, if they are required to pay damages $f^{*}(h)$, the injurers of types $q_{0}$ and $q_{1}$ will really adopt the expected behavior. The following lemma states precisely our results and gives the range where the liability must be changed.

Lemma 1: (a) There exists a unique solution $h^{*}$ to $D\left(\underline{h}, h^{*}\right)=0$, such that $\underline{h}<h^{*}<\left(q_{1} / q_{0}\right) \underline{h}$, and $D(\underline{h}, h)>0$ if, and only if, $h>h^{*}$. (b) When $D(\underline{h}, h) \leq 0$, damages $f=h / q_{1}$ induce the 
injurers of types $q_{0}$ and $q_{1}$ to choose respectively $s$ and $x^{*}(h)$. Otherwise (i.e. when $D(\underline{h}, h)>$ $0)$, damages $f=f^{*}(h)$ induce the injurers of type $q$ to choose $x^{*}\left(q f^{*}(h)\right)$.

From the above, it is clear that the liability schedule $f(h)$, for all $h$, resulting from steps 1 to 3 , is socially optimal. The next proposition summarizes our results and concludes our derivation of the optimal liability schedule.

Proposition $3\left(^{3}\right)$ : Let $s$ be a given safety standard. Define $\underline{h}$ such that $\underline{h}=c^{\prime}(s)$. There exists a unique $h^{*}$ satisfying $\underline{h}<h^{*}<\left(q_{1} / q_{0}\right) \underline{h}$ and $D\left(\underline{h}, h^{*}\right)=0$. It is socially optimal to induce the injurers of types $q_{0}$ and $q_{1}$ to choose:

$$
s \text {, if } h \leq \underline{h} \text {, }
$$
$s$ and $x^{*}(h)$, respectively, if $\underline{h}<h \leq h^{*}$, $x^{*}\left(q_{0} f^{*}(h)\right)$ and $x^{*}\left(q_{1} f^{*}(h)\right)$, respectively, if $h>h^{*}$.

These behaviors can be implemented if the damages $f(h)$, for all $h$, are given by:

$$
f(h)=h / q_{1}, \text { if } h \leq h^{*},=f^{*}(h), \text { if } h>h^{*} .
$$

Figure 4 below illustrates the normative rules in proposition 3.

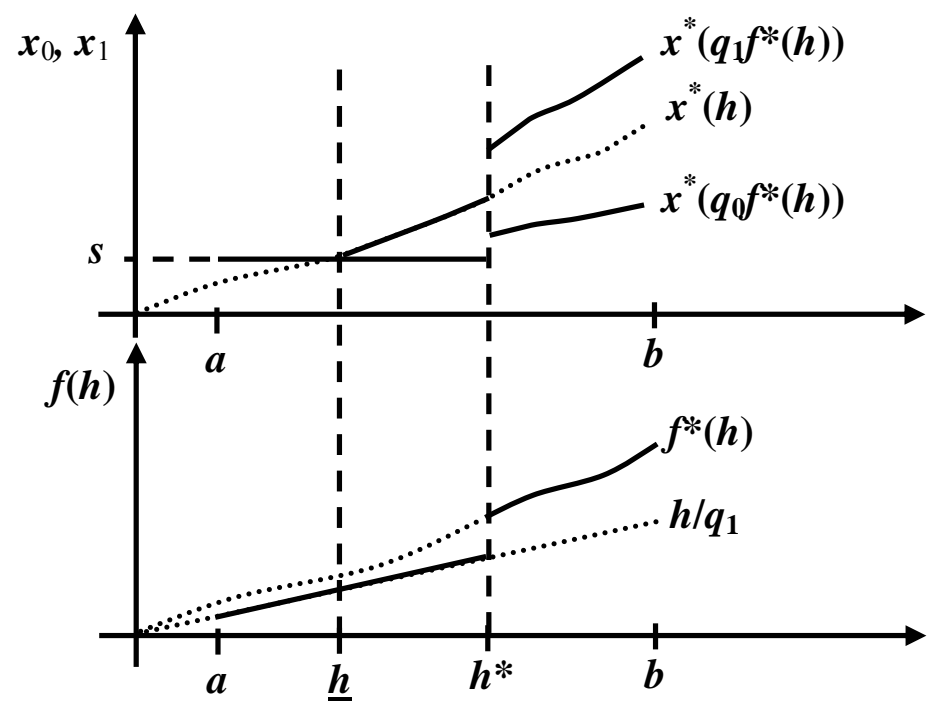

Figure 4 - Illustration of proposition 3 .

Optimal safety standard. In this section, we obtain a necessary condition for an optimal safety standard $s=x^{*}(\underline{h})$, assuming that the damages are chosen optimally.

Suppose that the optimal standard to be determined is such that $h^{*}<b$. When the damages are set according to the rules of proposition 3, the social problem (7) becomes to minimize over $s=x^{*}(\underline{h})$ :

$$
\begin{gathered}
\int_{a}^{\underline{h}}\{c(s)+(1-s) h\} \phi(h) \mathrm{d} h \\
+\int_{\underline{h}}^{h^{*}}\left\{r[c(s)+(1-s) h]+(1-r)\left[c\left(x^{*}(h)\right)+\left(1-x^{*}(h)\right) h\right]\right\} \phi(h) \mathrm{d} h \\
+\int_{h^{*}}^{b}\left\{r\left[c\left(x^{*}\left(q_{0} f^{*}(h)\right)\right)-x^{*}\left(q_{0} f^{*}(h)\right) h\right]+(1-r)\left[c\left(x^{*}\left(q_{1} f^{*}(h)\right)\right)-x^{*}\left(q_{1} f^{*}(h)\right) h\right]\right\} \phi(h) \mathrm{d} h,
\end{gathered}
$$

$\left({ }^{3}\right)$ Notice that this proposition allows two possible results, i.e. $h^{*}<b$ and $h^{*} \geq b$. Under the first condition, the damages schedule will induce in turn the three outcomes $(\mathrm{R}),(\mathrm{J})$ and $(\mathrm{L})$. Under the second, only outcomes $(\mathrm{R})$ and $(\mathrm{J})$ will occur. As $h^{*}<\left(q_{1} / q_{0}\right) \underline{h}$, the first case is always possible, provided that $\underline{h}$ is chosen sufficiently small. 
where $h^{*}$ is such that $D\left(\underline{h}, h^{*}\right)=0$.

The following proposition gives the first-order condition that an optimal safety standard must satisfy. The proof is given in the appendix.

Proposition $4\left({ }^{4}\right)$ : When the damages follow the terms of proposition 3 , if the optimal safety standard $s=x^{*}(\underline{h})$ satisfies $h^{*}<b$, it must lie strictly between $x^{*}(a)$ and $s^{*}$ and satisfy:

where $h^{*}$ is such that $D\left(\underline{h}, h^{*}\right)=0$.

$$
r \int_{a}^{h^{*}}(\underline{h}-h) \phi(h) \mathrm{d} h+(1-r) \int_{a}^{\underline{h}}(\underline{h}-h) \phi(h) \mathrm{d} h=0,
$$

A point to be remembered from proposition 4 is that the computation of the optimal standard is in fact governed by a simple rule. Precisely, it should be set so that the marginal cost of precaution $c^{\prime}(s)=\underline{h}$ equals the average harm among the subset of the population that adopts it. This follows directly from the first-order condition in proposition 4, which is equivalent to:

$$
c^{\prime}(s)=\frac{r \int_{a}^{h^{*}} h \phi(h) \mathrm{d} h+(1-r) \int_{a}^{\underline{h}} h \phi(h) \mathrm{d} h}{r \int_{a}^{h^{*}} \phi(h) \mathrm{d} h+(1-r) \int_{a}^{\underline{h}} \phi(h) \mathrm{d} h}
$$

and from proposition 3 , which states that the regulatory standard is followed by injurers of types $q_{0}$ and $h \leq h^{*}$, on the one hand, and of types $q_{1}$ and $h \leq \underline{h}$, on the other hand.

\section{Appendix}

\section{Preliminary lemmas}

In the proofs below, we let $k\left(h^{*}, h\right)$ be defined, for all $h^{*}$ and $h$, by:

$$
k\left(h^{*}, h\right)=c\left(x^{*}\left(h^{*}\right)\right)+\left(1-x^{*}\left(h^{*}\right)\right) h,
$$

and we make an extensive use of the following lemmas:

\section{Lemmas:}

i) The function $k\left(h^{*}, h\right)$ is differentiable with respect to both arguments, with:

$$
\begin{gathered}
k_{1}\left(h^{*}, h\right)=\left(c^{\prime}\left(x^{*}\left(h^{*}\right)\right)-h\right)\left(x^{*}\right)^{\prime}\left(h^{*}\right)=\left(h^{*}-h\right) / c^{\prime \prime}\left(x^{*}\left(h^{*}\right)\right) ; \\
k_{2}\left(h^{*}, h\right)=1-x^{*}\left(h^{*}\right) \geq 0 ;
\end{gathered}
$$

ii) As a function of $h^{*}$, it has a strict minimum at $h^{*}=h$ and is U-shaped (i.e. it is decreasing for $h^{*}<h$, and increasing for $h^{*}>h$ );

iii) For all $h$, it is strictly convex in $h^{*}$ over a neighborhood $\left.V=\right] h-\varepsilon, h+\varepsilon[$ of $h$.

\section{Proof:}

Lemmas i) and ii) are immediate.

To prove lemma iii), assume that $c$ "' $(x)$ is differentiable. Then, by lemma i) and equation (2), the second-order derivative of $k\left(h^{*}, h\right)$, with respect to $h^{*}$, is:

$$
k_{11}\left(h^{*}, h\right)=\left\{1-\left(h^{*}-h\right) c " "\left(x^{*}\left(h^{*}\right)\right) / c^{\prime \prime}\left(x^{*}\left(h^{*}\right)\right)^{2}\right\} / c^{\prime \prime}\left(x^{*}\left(h^{*}\right)\right) .
$$

Let $1 / \varepsilon=\operatorname{Sup}\left\{\left|c^{\prime \prime \prime}(x)\right| / c^{\prime \prime}(x)^{2} ; 0 \leq x<1\right\}\left(^{5}\right)$. For all $h^{*}$ such that $\left|h^{*}-h\right|<\varepsilon$, we have:

$$
\left(h^{*}-h\right) c c^{\prime \prime}\left(x^{*}\left(h^{*}\right)\right) / c^{\prime \prime}\left(x^{*}\left(h^{*}\right)\right)^{2} \leq\left|h^{*}-h\right||c " '(x)| / c^{\prime \prime}(x)^{2}<1 \text {. }
$$

$\left({ }^{4}\right)$ If the optimal safety standard is such that $h^{*} \geq b$, a similar proposition holds. It can be derived simply from this proposition, by writing $h^{*}=b$ instead of $D\left(\underline{h}, h^{*}\right)=0$.

$\left({ }^{5}\right) \varepsilon$ is well defined, since if $\operatorname{Sup}\left\{\left|C^{\prime \prime}(x)\right| / c "(x)^{2} ; 0 \leq x<1\right\}=0$, then $c^{\prime \prime}(x)=0$, for all $x$, and $c(x)$ is quadratic. This contradicts our assumption that $c^{\prime}(x) \rightarrow \infty$ when $x \rightarrow 1$. 
It follows that $k_{11}\left(h^{*}, h\right)>0$, for all $h^{*}$ such that $\left|h^{*}-h\right|<\varepsilon$. $\square$

\section{Proof of Proposition 1}

By definition of $k\left(h^{*}, h\right)$, the social problem $(5)$ is to minimize over $f$ :

$$
r k\left(q_{0} f, h\right)+(1-r) k\left(q_{1} f, h\right) .
$$

This problem has a solution, for only values of $f$ such that $h / q_{1} \leq f \leq h / q_{0}$ ought to be considered, by lemma ii), and the objective function is continuous.

For all $f$ such that $h / q_{1} \leq f \leq h / q_{0}$, we have: $q f \in\left[\left(q_{0} / q_{1}\right) h,\left(q_{1} / q_{0}\right) h\right]$, where $q=q_{0}$ or $q_{1}$. If $q_{1} / q_{0}$ is small enough (actually, if $q_{1} / q_{0}<1+\varepsilon / b$ ), then whatever $f, h$ and $q$ (with $h / q_{1} \leq f \leq$ $h / q_{0}, a \leq h \leq b$ and $\left.q=q_{0}, q_{1}\right), q f \in V$ and lemma iii) implies that the expected social cost (5) is strictly convex in $f$ (as the sum of two strictly convex functions, $k(q f, h)$, with $q=q_{0}, q_{1}$ ). Hence, the social problem (5) has a unique solution $f^{*}(h)$, for all $h$.

For all $h$, the optimal solution $f^{*}(h)$ must satisfy the first-order condition:

$$
r\left(q_{0} f-h\right) q_{0} / c^{\prime \prime}\left(x^{*}\left(q_{0} f\right)\right)+(1-r)\left(q_{1} f-h\right) q_{1} / c^{\prime \prime}\left(x^{*}\left(q_{1} f\right)\right)=0 .
$$

Since $c^{\prime \prime}(x)>0,0<q_{0}<q_{1}$ and $0<r<1$, this condition implies that: $h / q_{1}<f^{*}(h)<h / q_{0}$.

If $q_{1} / q_{0}$ is sufficiently small, the following second-order condition holds (if $q_{1} / q_{0}<1+\varepsilon / b$, then the expected social cost is locally strictly convex in a neighborhood of $\left.f^{*}(h)\right)$ :

$$
\begin{aligned}
\Delta= & r\left(q_{0}\right)^{2} / c^{\prime \prime}\left(x^{*}\left(q_{0} f^{*}(h)\right)\right)\left\{1-\left(q_{0} f^{*}(h)-h\right) c^{\prime \prime \prime}\left(x^{*}\left(q_{0} f^{*}(h)\right)\right) /\left[c^{\prime \prime}\left(x^{*}\left(q_{0} f^{*}(h)\right)\right)\right]^{2}\right\} \\
& +(1-\mathrm{r})\left(q_{1}\right)^{2} / c^{\prime \prime}\left(x^{*}\left(q_{1} f^{*}(h)\right)\right)\left\{1-\left(q_{1} f^{*}(h)-h\right) c^{\prime \prime}\left(x^{*}\left(q_{1} f\right)\right) /\left[c^{\prime \prime}\left(x^{*}\left(q_{1} f^{*}(h)\right)\right)\right]^{2}\right\}>0 .
\end{aligned}
$$

Thus, the first-order condition implicitly defines $f^{*}(h)$ as a differentiable and increasing function of $h$ :

$$
\mathrm{d} f^{*} / \mathrm{d} h=\left[r q_{0} / c^{\prime \prime}\left(x^{*}\left(q_{0} f^{*}(h)\right)\right)+(1-\mathrm{r}) / c^{\prime \prime}\left(x^{*}\left(q_{1} f^{*}(h)\right)\right)\right] / \Delta>0 .
$$

\section{Proof of Proposition 2}

In this proof, we let $f^{*}$ satisfy (A1), for all $h$ and $r$ :

$$
r\left(q_{0} f^{*}-h\right) q_{0} / c^{\prime \prime}\left(x^{*}\left(q_{0} f^{*}\right)\right)+(1-r)\left(q_{1} f^{*}-h\right) q_{1} / c^{\prime \prime}\left(x^{*}\left(q_{1} f^{*}\right)\right)=0 .
$$

This notation is imprecise, for $f^{*}$ is in fact a function of $h$ and $r$, but simplifies the expressions. For the same reason, we will use the notations $C_{0}=c^{\prime \prime}\left(x^{*}\left(q_{0} f^{*}\right)\right)$ and $C_{1}=c^{\prime \prime}\left(x^{*}\left(q_{1} f^{*}\right)\right)$.

For all $h$, let $L(h, r)$ be the minimum of the expected social cost (5) when liability is used alone:

$$
L(h, r)=r k\left(q_{0} f^{*}, h\right)+(1-r) k\left(q_{1} f^{*}, h\right) .
$$

The first-best expected social cost is achievable if, and only if, $r=0$ or $r=1\left({ }^{6}\right)$. Hence we have, whenever $0<r<1$ :

$$
L(h, r)>L(h, 0)=L(h, 1)=c\left(x^{*}(h)\right)+\left(1-x^{*}(h)\right) h .
$$

The first-order condition (A1) defines implicitly $f^{*}$ as a differentiable and increasing function of $r\left({ }^{7}\right)$ :

where $\Delta>0$ (cf. proof of proposition 1). From this, we obtain $\left(^{8}\right)$ :

$$
\mathrm{d} f^{*} / \mathrm{d} r=\left[\left(q_{1} f^{*}-h\right) q_{1} / C_{1}-\left(q_{0} f^{*}-h\right) q_{0} / C_{0}\right] / \Delta>0
$$

$$
\mathrm{d}^{2} L(h, r) / \mathrm{d} r^{2}=\left[\left(q_{0} f^{*}-h\right) q_{0} / C_{0}-\left(q_{1} f^{*}-h\right) q_{1} / C_{1}\right] \mathrm{d} f^{*} / \mathrm{d} r=-\Delta\left(\mathrm{d} f^{*} / \mathrm{d} r\right)^{2}<0 .
$$

Therefore, $L(h, r)$ is strictly concave with respect to $r$.

It is clear that the expected social cost:

$$
L(r)=E(L(h, r))=\int_{a}^{b} L(h, r) \phi(h) \mathrm{d} h,
$$

$\left({ }^{6}\right)$ If $r=0$, damages $f^{*}=h / q_{1}$ induce injurers of type $q_{1}$ to choose $x^{*}(h)$. If $r=1$, damages $f^{*}=h / q_{1}$ induce injurers of type $q_{0}$ to choose $x^{*}(h)$.

$\left(^{7}\right)$ Notice that, since $f^{*}$ satisfies the first-order condition (A1), we have:

$\left(q_{1} f^{*}-h\right) q_{1} / C_{1}-\left(q_{0} f^{*}-h\right) q_{0} / C_{0}=-\left[\left(q_{0} f^{*}-h\right) q_{0} / C_{0}\right] /(1-r)=\left[\left(q_{1} f^{*}-h\right) q_{1} / C_{1}\right] / r>0$.

$\left({ }^{8}\right)$ Use first the envelope theorem to get: $\mathrm{d} L(h, r) / \mathrm{d} r=k\left(q_{0} f^{*}, h\right)-k\left(q_{1} f^{*}, h\right)$. Then use lemma ii). 
adopts the properties of $L(h, r)$. That is, it has a strict minimum for $r=0$ and $r=1$, given by:

$$
L(0)=L(1)=\int_{a}^{b}\left[c\left(x^{*}(h)\right)+\left(1-x^{*}(h)\right) h\right] \phi(h) \mathrm{d} h,
$$

and is strictly concave in $r$. Consequently, $L(r)$ is reversed U-shaped and has a unique maximum at $\underline{r}$, with $0<\underline{r}<1$.

Define:

$$
R(\phi)=\int_{a}^{b}\left[c\left(s^{*}\right)+\left(1-s^{*}\right) h\right] \phi(h) \mathrm{d} h,
$$

the minimum expected cost when regulation is used alone. By choosing a density $\phi(h)$ so that the probability mass is sufficiently concentrated around the mean $E(h), R(\phi)$ can be made arbitrarily close to the first-best expected social cost. In particular, it is always possible to choose a density $\phi(h)$ so that:

$$
L(\underline{r})<R(\phi)<L(0)=L(1)
$$

From the property of $L(r)$, there exists $r_{0}$ and $r_{1}$, with $r_{0}<\underline{r}<r_{1}$, such that $L\left(r_{0}\right)=L\left(r_{1}\right)=$ $R(\phi) . L(r)$ is increased if $r$ is such that $r_{0}<r<r_{1}$, and $R(\phi)$ is decreased if $\phi(h)$ is more concentrated around $E(h)$, and conversely.

\section{Proof of Lemma 1}

In this proof, only $h>\underline{h}$ are considered.

a) By definition of $k\left(h^{*}, h\right)$, we have:

$D(\underline{h}, h)=\left[r k(\underline{h}, h)+(1-r) k\left(\min \left\{h,\left(q_{1} / q_{0}\right) \underline{h}\right\}, h\right)\right]-\left[r k\left(q_{0} f^{*}(h), h\right)+(1-r) k\left(q_{1} f^{*}(h), h\right)\right]$.

Notice first that $D(\underline{h}, \underline{h})<0<D\left(\underline{h},\left(q_{1} / q_{0}\right) \underline{h}\right)\left({ }^{9}\right)$. Then, as $D(\underline{h}, h)$ is continuous in $h$, there exists $h^{*}$ such that:

Now we need to prove that:

$$
\underline{h}<h^{*}<\left(q_{1} / q_{0}\right) \underline{h} \text { and } D\left(\underline{h}, h^{*}\right)=0 .
$$

$$
D(\underline{h}, h)>0, \text { for all } h>h^{*} .
$$

For $h \geq\left(q_{1} / q_{0}\right) \underline{h}$, the case has been shown in footnote (9).

For $h<\left(q_{1} / q_{0}\right) \underline{h}$, remark first that $D\left(\underline{h}, h^{*}\right)=0$ implies that $\underline{h}<q_{0} f^{*}\left(h^{*}\right)\left({ }^{10}\right)$. Thus, as $f^{*}(h)$ is increasing, for all $h \geq h^{*}, \underline{h}<q_{0} f^{*}(h)$. In turn, from proposition 1, we prove that, for all $h \geq h^{*}$, $\underline{h}<q_{0} f^{*}(h)<h<q_{1} f^{*}(h)$. Finally, as $x^{*}(h)$ is increasing, we get:

$$
x^{*}(\underline{h})<x^{*}\left(q_{0} f^{*}(h)\right)<x^{*}(h)<x^{*}\left(q_{1} f^{*}(h)\right) \text {, for all } h \geq h^{*} .
$$

Now, $D(\underline{h}, h)$ is differentiable with respect to $h$ and:

$$
D_{2}(\underline{h}, h)=r\left(x^{*}\left(q_{0} f^{*}(h)\right)-x^{*}(\underline{h})\right)+(1-r)\left(x^{*}\left(q_{1} f^{*}(h)\right)-x^{*}(h)\right) .
$$

From (A4), whenever $h^{*}<h<\left(q_{1} / q_{0}\right) \underline{h}, D_{2}(\underline{h}, h)>0$. This ends the proof of claim (A3).

Uniqueness follows from (A2) and (A3).

b) If $\underline{h}<h \leq h^{*}$, let $f=h / q_{1}$. We have: $q_{0} f=\left(q_{0} / q_{1}\right) h \leq\left(q_{0} / q_{1}\right) h^{*}<\underline{h}$ (from (A2)) and $q_{1} f=h$ $\geq \underline{h}$. Hence, $x_{0}=\max \left\{s, x^{*}\left(q_{0} f\right)\right\}=s$ and $x_{1}=\max \left\{s, x^{*}\left(q_{1} f\right)\right\}=x^{*}(h)$. Otherwise (if $\left.h>h^{*}\right)$, from (A4), $x_{0}=\max \left\{s, x^{*}\left(q_{0} f^{*}(h)\right)\right\}=x^{*}\left(q_{0} f^{*}(h)\right)$ and $x_{1}=\max \left\{s, x^{*}\left(q_{1} f^{*}(h)\right)\right\}=x^{*}\left(q_{1} f^{*}(h)\right)$.

\section{Proof of Proposition 4}

$\left(^{9}\right)$ By lemma ii), $k(\underline{h}, \underline{h})$ is smaller than $k\left(q_{0} f^{*}(\underline{h}), h\right)$ and than $k\left(q_{1} f^{*}(h), h\right)$. Therefore, $D(\underline{h}, \underline{h})<0$. To prove that $D\left(\underline{h},\left(q_{1} / q_{0}\right) \underline{h}\right)>0$, let $h \geq\left(q_{1} / q_{0}\right) \underline{h}$ and $f=\underline{h} / q_{0}$. We have:

$D(\underline{h}, h)=\left[r k\left(q_{0} f, h\right)+(1-r) k\left(q_{1} f, h\right)\right]-\left[r k\left(q_{0} f^{*}(h), h\right)+(1-r) k\left(q_{1} f^{*}(h), h\right)\right]$.

From proposition 1 , the first term under square brackets is minimized if, and only if, $f=f^{*}(h)$. As $f=\underline{h} / q_{0} \leq h / q_{1}$ and $h / q_{1}<f^{*}(h)<h / q_{0}, f \neq f^{*}(h)$ and $D(\underline{h}, h)>0$, for all $h \geq\left(q_{1} / q_{0}\right) \underline{h}$. In particular, $D\left(\underline{h},\left(q_{1} / q_{0}\right) \underline{h}\right)>0$.

$\left({ }^{10}\right)$ By lemma ii), if $\underline{h} \geq q_{0} f^{*}\left(h^{*}\right)$, then $k\left(\underline{h}, h^{*}\right) \leq k\left(q_{0} f^{*}\left(h^{*}\right), h^{*}\right)$, and $k\left(h^{*}, h^{*}\right)<k\left(q_{1} f^{*}\left(h^{*}\right), h^{*}\right)$. This implies that $D\left(\underline{h}, h^{*}\right)<0$. 
Assume that the optimal safety standard $s=x^{*}(\underline{h})$ to be determined is such that $D\left(\underline{h}, h^{*}\right)=$ 0 occurs for $h^{*}<b$. Assume that damages $f(h)$, for all $h$, are defined as in proposition 3 . The social problem is to minimize over $\underline{h}$ the expected social cost:

$$
\begin{gathered}
\int_{a}^{\underline{h}} k(\underline{h}, h) \phi(h) \mathrm{d} h+\int_{\underline{h}}^{h^{*}}[r k(\underline{h}, h)+(1-r) k(h, h)] \phi(h) \mathrm{d} h \\
+\int_{h^{*}}{ }^{b}\left[r k\left(q_{0} f^{*}(h), h\right)+(1-r) k\left(q_{1} f^{*}(h), h\right)\right] \phi(h) \mathrm{d} h,
\end{gathered}
$$

subject to $D\left(\underline{h}, h^{*}\right)=0$.

The constraint $D\left(\underline{h}, h^{*}\right)=0$ defines implicitly $h^{*}$ as a differentiable function of $\underline{h}$, with $\left({ }^{11}\right)$ : $\mathrm{d} h * / \mathrm{d} \underline{h}=-D_{1}\left(\underline{h}, h^{*}\right) / D_{2}\left(\underline{h}, h^{*}\right)>0$.

Therefore, an optimal standard must verify the first-order condition (eliminating certain terms, in particular $D\left(\underline{h}, h^{*}\right)=0$, and multiplying by $\left.c^{\prime \prime}\left(x^{*}(\underline{h})\right)\right)$ :

$$
F(\underline{h}) \equiv r \int_{a}^{h^{*}}(\underline{h}-h) / \phi(h) \mathrm{d} h+(1-r) \int_{a}^{\underline{h}}(\underline{h}-h) \phi(h) \mathrm{d} h=0,
$$

where $h^{*}$ is such that $D\left(\underline{h}, h^{*}\right)=0$.

We have:

$$
\begin{gathered}
F(a)=r \int_{a}^{h^{*}}(a-h) \phi(h) \mathrm{d} h<0, \\
F(E(h))>\int_{a}^{b}(E(h)-h) \phi(h) \mathrm{d} h=0 .
\end{gathered}
$$

It follows that $s=x^{*}(\underline{h})$ must lie between $s=x^{*}(\underline{h})$ and $s=x^{*}(\underline{h})$.

\section{References}

Cooter, R.D. (1991), "Economic Theories of Legal Liability", Journal of Economic Perspectives, 5 (3) : 11-30.

Kaplow, L. and S. Shavell (2002), "Economic analysis of law", in Handbook of Public Economics, Volume 3, Alan J. Auerbach and Martin Feldstein (editors), Elsevier, 2002, pages 1661-1784.

Mookherjee D. and I.P.L. Png (1992), "Monitoring vis-à-vis investigation in enforcement of law", American Economic Review, 82 (3) : 556-565.

Polinsky, A.M. and S. Shavell (1998a), "Punitive Damages", The New Palgrave Dictionary of Economics and the Law, Volume 3 (P-Z), Peter Newman (editor), Stockton Press, New York, 1998, pages 192-198.

Polinsky A.M. and S. Shavell (1998b), "Punitive Damages: An Economic Analysis", Harvard Law Review, 111(4): 869-962.

Rouillon, S. (2005), "La responsabilité civile face à l'arbitrage entre la précaution et l'évasion", 22-ièmes Journées de Microéconomie Appliquée, Hammamet, Tunisie.

Rouillon, S. (2007), "Variable Probabilities of Suit and Liability Rules", Working Paper, Université Bordeaux 4.

Schmitz, P.W. (2000), "On the joint use of liability and safety regulation", International Review of Law and Economics, $20: 371-382$.

Shavell, S. (1984a), “A Model of Optimal Use of Liability and Safety Regulation”, Rand Journal of Economics, 15 (2) : 271-280.

Shavell, S. (1984b), "Liability for Harm versus Regulation of Safety", Journal of Legal Studies, $13(2): 357-374$.

Wittman, D. (1977), "Prior Regulation versus Post Liability: The Choice between Input and Output Monitoring”, Journal of Legal Studies, 6 (1) : 193-211.

$\left({ }^{11}\right)$ Since $\underline{h}<h^{*}<\left(q_{1} / q_{0}\right) \underline{h}, \min \left\{h,\left(q_{1} / q_{0}\right) \underline{h}\right\}=h$ over a neighborhood of $h^{*}$. Thus, $D(\underline{h}, h)$ is differentiable, with $D_{1}\left(\underline{h}, h^{*}\right)=r\left(\underline{h}-h^{*}\right) / c^{\prime \prime}\left(x^{*}(\underline{h})\right)<0\left(\right.$ since $\left.\underline{h}<h^{*}\right)$ and $D_{2}\left(\underline{h}, h^{*}\right)>0$ (cf. (A4) and (A5)). 